OPEN ACCESS

Edited by:

Youji Wang,

Shanghai Ocean University, China

Reviewed by:

Guangcheng Chen,

Third Institute of Oceanography, State

Oceanic Administration, China

Shengyan Tian,

Tianjin University of Science

and Technology, China

*Correspondence:

Xiaoshou Liu

liuxs@ouc.edu.cn

Specialty section:

This article was submitted to

Marine Pollution,

a section of the journal

Frontiers in Marine Science

Received: 01 July 2021

Accepted: 20 August 2021

Published: 22 September 2021

Citation:

$L u X, X u J, X u Z D$ and Liu XS (2021) Assessment of Benthic Ecological Quality Status Using

Multi-Biotic Indices Based on Macrofaunal Assemblages in a

Semi-Enclosed Bay.

Front. Mar. Sci. 8:734710. doi: 10.3389/fmars.2021.734710

\section{Assessment of Benthic Ecological Quality Status Using Multi-Biotic Indices Based on Macrofaunal Assemblages in a Semi-Enclosed Bay}

\author{
Xin $\mathrm{Lu}^{1,2}$, Jing $X \mathrm{u}^{1,2}$, Zhaodong $X u^{3}$ and Xiaoshou Liu ${ }^{1,2 *}$ \\ 'College of Marine Life Sciences and Frontiers Science Center for Deep Ocean Multispheres and Earth System, Ocean \\ University of China, Qingdao, China, ${ }^{2}$ Institute of Evolution and Marine Biodiversity, Ocean University of China, Qingdao, \\ China, ${ }^{3}$ North China Sea Environmental Monitoring Center, State Oceanic Administration, Qingdao, China
}

Semi-enclosed bays have physical and chemical characteristics influenced by both land and sea systems and the quality of the benthic environment is always of great concern. Macrofauna are considered good indicators for evaluating the benthic ecological quality status owing to their biological characteristics. In this study, six biotic indices, namely the Shannon-Wiener diversity index $\left(H^{\prime}\right)$, Abundance-Biomass Comparison (ABC) curve, AZTI's Marine Biotic Index (AMBI), multivariate-AMBI (M-AMBI), BOPA index, and BENTIX index, were used to evaluate the adaptability of different biological indices in the bioassessment of the benthic environment in a semi-enclosed bay. In the annual environmental assessment of the study area, the average values of the six indices $\left(H^{\prime}\right.$, ABC curve, AMBI, M-AMBI, BOPA, and BENTIX) were 4.494, 0.182, 2.433, 0.791, 0.033 , and 3.813, respectively; accordingly, $H^{\prime}, \mathrm{M}-\mathrm{AMBI}$, and BOPA met the high standards whereas the other indices met the good standards, indicating that the whole study bay was slightly disturbed and had good ecological quality. From the perspective of spatial variation, the benthic environment in the middle of the bay was better than that in the north; the environmental problems in the northeast were particularly noteworthy. In terms of temporal patterns, the benthic environment in winter and summer was significantly better than that in spring and autumn, with obvious seasonal differences. The present results indicate that the $H^{\prime}$ and $A B C$ curve based on benthic abundance and biomass should be avoided for environmental assessment in mariculture areas. AMBI and $\mathrm{M}-\mathrm{AMBI}$ should be used with caution when the percentage of unassigned species is high, in which case $H^{\prime}$ is the appropriate choice. When there are few unassigned species, $\mathrm{M}-\mathrm{AMBI}$ is more conducive for accurate evaluation of the benthic environment than $\mathrm{AMBI}$ and $H^{\prime}$.

Keywords: semi-enclosed bay, macrofauna, biotic index, ecological quality status, Shannon-Wiener diversity index, $A M B I$ and $M-A M B I$ 


\section{INTRODUCTION}

Compared with the pelagic ecosystems, benthic ecosystems have high species diversity. The species number of marine benthic invertebrates accounts for $90 \%$ in the total marine invertebrates (Xu, 2011). Marine benthic organisms can be divided into macrofauna, meiofauna, and microfauna, according to their body size. As vital components of the benthic food web, they play important roles through complex trophic relationships in the material cycle and energy flow of benthic ecosystems. Macrofaunal communities contribute to promote biogeochemical processes by altering the roughness, original structure, and chemical properties of sediments through activities such as feeding, digging, and tube-building (Graf and Rosenberg, 1997; Snelgrove, 1998). The diversity of macrofaunal assemblages is also an indispensable indicator for evaluating the benthic ecological quality status (Huang et al., 2021). Most of macrofauna live on the bottom surface or inside of sediment and usually have weak migration capacities (Pelletier et al., 2010; Ji et al., 2016; Feng et al., 2021). In addition, different species of macrofauna differ in their adaptability to environmental conditions, tolerance and sensitivity to adverse factors such as pollution (Snelgrove, 1998). Macrofauna have often been used to indicate the quality of benthic environments (Pinto et al., 2008; Li et al., 2020) as the relationship between macrofauna communities and the degree of disturbance has been analyzed by previous studies (Zheng et al., 2011; Egres et al., 2019; Yoon et al., 2021).

The negative effects of industry, tourism, maritime transportation, fisheries, and aquaculture on biodiversity are noteworthy in coastal ecosystems (Simboura and Zenetos, 2002). Frequent human activities lead to heavy metal pollution, persistent organic pollutants, eutrophication, seawater acidification, and other issues, changing the structure of marine biological communities and marine biogeochemical cycles and ultimately affecting the structure and function of marine ecosystems (Lv et al., 2016). For example, the reclamation project in Bohai Bay and the expansion of Tianjin Port have permanently occupied coastal tidal flats, weakening the selfpurification capacity and tidal current hydrodynamic force and causing sediment deposition and topographic change, which have a serious impact on the coastal ecosystem (Nie and Tao, 2008; Zhang et al., 2015; Xu et al., 2021). Increasingly frequent human activities in the Yangtze River and adjacent waters have led to substantial increases in the concentrations of nitrogen and phosphorus in seawater, causing marine pollution events such as red tides (Huang et al., 2003; Liu et al., 2013). Many restaurants and entertainment facilities built in the Zhoushan Islands in the East China Sea to develop tourism have discharged untreated sewage into seawater and accelerated the degradation of the marine benthic environment (Zhang et al., 2017). Overfishing in coastal systems, especially bottom trawling, also has a significant impact on benthic communities, resulting in a decrease in community diversity (Li et al., 2020).

In coastal systems, a semi-enclosed bay has wide water area and small waves, so it is an ideal place for development of aquaculture and port shipping. However, owing to the integration of the physical and chemical properties of land and ocean systems
(Gao et al., 2021), the ecological environment has potential instability. Environmental problems such as small tidal volume, poor water exchange capacity, and significant influence of human activities have become increasingly noteworthy (Lim et al., 2012; Peng et al., 2013). Jiaozhou Bay is a typical semi-closed bay located on the southern coast of the Shandong Peninsula and is surrounded by densely populated urban areas and coastal industrial areas (Song et al., 2020). The inner bay has wide harbors, deep waters, and calm winds and waves, and the sea is not frozen all year round. It is a natural bay with many rivers flowing into it. The dual effects of frequent human activities and excellent natural conditions make it an ideal area for testing the adaptability of biological indices to semi-enclosed bays.

Shannon-Wiener diversity index $\left(H^{\prime}\right)$, Abundance-Biomass Comparison (ABC) curve, AZTI's Marine Biotic Index (AMBI), multivariate-AMBI (M-AMBI), BOPA index, and BENTIX were used to evaluate the spatial and temporal variation of benthic ecological quality in Jiaozhou Bay. The results of the assessment are also combined with environmental parameters to analyze the environmental quality of Jiaozhou Bay and further explore the impact of anthropogenic activities on the benthic environment. At the same time, taking Jiaozhou Bay as an example, the applicability of different biotic indices in environmental assessment of a semi-enclosed bay was explored and compared. The main advantages and constraints of each indicator are briefly summarized.

Considering the principles of the six indicators, the following assumptions are proposed: (1) The indexes based on biomass have limitations in shellfish farming areas. (2) M-AMBI is calculated by combining AMBI and $H^{\prime}$, so it can better explain the status of environmental quality.

\section{MATERIALS AND METHODS}

\section{Field Sampling}

Jiaozhou Bay is a $32 \mathrm{~km}$ long and $27 \mathrm{~km}$ wide semi-enclosed bay, located in the south of the Shandong Peninsula $\left(35^{\circ} 38^{\prime}-36^{\circ} 18^{\prime} \mathrm{N}\right.$, $120^{\circ} 04^{\prime}-120^{\circ} 23^{\prime} \mathrm{E}$ ). It is a temperate monsoonal climate zone. The tide is a typical semi-diurnal tide. The deposits of Jiaozhou Bay are terrigeneous and organic matter content is $0.38-1.91 \%$ which is increasing with time (Wang et al., 2017). In the early 1980s, Jiaozhou Bay was designated as a pilot area for the research and development of marine resources. There are abundant species of macrofauna in the bay and is one of the earliest typical areas to carry out bay ecology research in China (Yu et al., 2006; Yang et al., 2016). With the rapid development of coastal farming and reclamation has resulted in the gradual transformation of most of the coastline from natural to artificial areas ( $\mathrm{Fu}$ et al., 2018; Quan et al., 2020b; Yin et al., 2021), leading to a decrease in tidal intake and a weakened self-purification ability (Zhang et al., 2021). In addition, the water quality of Jiaozhou Bay is also affected by industrial and domestic wastewater from many surrounding rivers, including some nutrients, heavy metals, and some organic pollutants, as well as some petroleum and reactive phosphate pollutants from ship operations and fishing vessels (Melet et al., 2020; Gu et al., 2021a). Collectively, all factors 
put great pressure on the benthic environment of Jiaozhou Bay, causing different degrees of disturbance to benthic organisms and the benthic environment.

Macrofauna were collected from 14 sampling sites (J1-J14) in Jiaozhou Bay during four cruises in February, May, August, and November 2014, representing winter, spring, summer, and autumn cruises, respectively (Figure 1). The sites of each cruise were set consistently, but the J6 site sample was not collected during the spring and autumn cruises. Sites J1-J7 are located near Jiaozhou Bay Bridge, which was built in 2006 and completed in 2011. J2 and J6 are near the Licun River and Dagu River, respectively, which are affected by the impact of the river. J2 and J3 are located in shellfish aquaculture area. J13 and J14 are located at the junction of Jiaozhou Bay and the Yellow Sea. The 14 sites were evenly distributed in most areas of Jiaozhou Bay, reflecting the status of macrofauna and the environment. Sediment samples were collected and washed on deck using a $0.05 \mathrm{~m}^{2}$ box corer, and four replicate samples were combined into one sample. These samples were subsequently preserved in $75 \%$ ethanol until laboratory identification macrofauna analysis.

To characterize the abiotic environment, the water depth, bottom water temperature, salinity, and $\mathrm{pH}$ at all stations were measured using a YSI 600XLM Multi-Parameter Water Quality Sonde (YSI Incorporated, United States) in situ. At the same time, surface sediments were sampled for the analysis of sediment water content $(\mathrm{W})$, organic matter content (OM), and median grain size (Md), chlorophyll $a$ content (Chl- $a$ ) and pheophorbide content (Pha). They were stored in $-20^{\circ} \mathrm{C}$ refrigerator until analysis in the laboratory.

\section{Laboratory Analysis}

In the laboratory, the sediment samples were stained with Rose Bengal overnight; then, the samples were sieved with a $0.5 \mathrm{~mm}$ mesh sieve to collect all macrofaunal organisms. All animals were sorted and identified to the lowest possible taxonomic level using a stereo microscope. Density (ind. $/ \mathrm{m}^{2}$ ), and biomass (wet weight, $\mathrm{g} / \mathrm{m}^{2}$ ) were determined using a $0.1 \mathrm{mg}$ precision electric balance (Eleftherious and McIntyre, 2013). The sediment grain size was measured using a laser particle size analyzer (Master Sizer 3000, China), and Chl- $a$ and Pha were determined by F96Pro Fluorescence Spectrophotometry (Shanghai Lengguang Technology Co., Ltd., China).

\section{Statistical Analysis}

Microsoft Excel 2019 (Microsoft, United States), PRIMER 6.0 software package (PRIMER-E, United Kingdom), SPSS 22.0 (SPSS, United States), and ArcGIS 10.6 (Esri, United States) were used for data analysis and geographic mapping. The calculation processes of indices are in Supplementary Material.

\section{Evaluation Standard}

The European Water Framework Directive (WFD) issued by the European Union in 2000 recommended that the status of ecological environmental quality be divided into five grades; hence, all the evaluation indices in this study eventually divided the status of ecological environmental quality into five grades: high, good, moderate, poor, and bad (Table 1).

\section{Correlation Analysis}

The correlation analysis between the biological index $\left(H^{\prime}\right.$, $W$, AMBI, M-AMBI, BOPA, and BENTIX) and physical and chemical factors was used to test the response of the biological index to human environmental pressure. Pearson correlation analysis was used for correlation significance, which was performed using SPSS 22.0.

\section{RESULTS}

\section{Community Structure}

A total of 251 species of macrofauna belonging to 10 phyla were identified. The mean macrofaunal abundance and biomass values were 2259.39 ind. $/ \mathrm{m}^{2}$ and $501.88 \mathrm{~g} / \mathrm{m}^{2}$, respectively. Polychetes were the most dominant group, accounting for $41 \%$ of the total species and $52 \%$ of the total abundance, followed by crustaceans, mollusks, and echinoderms.

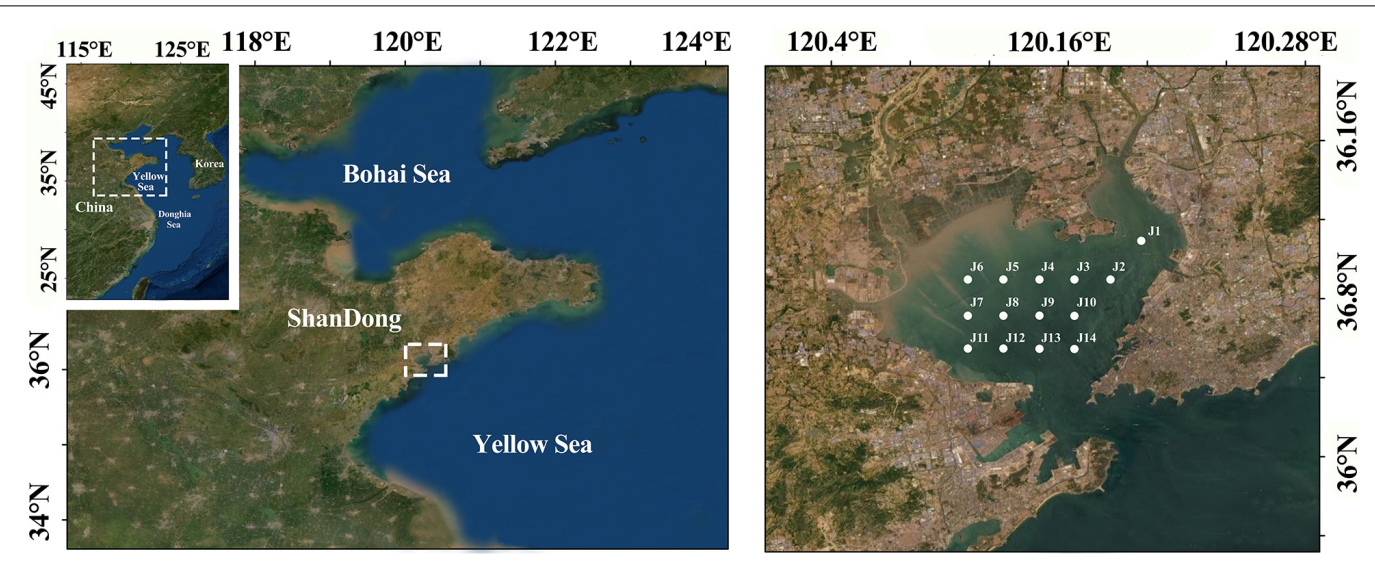

FIGURE 1 | Study area and locations of sampling sites in coastal waters of Jiaozhou Bay. 
TABLE 1 | Threshold levels of six indices for benthic ecological quality status assessment.

\begin{tabular}{|c|c|c|c|c|c|c|}
\hline Benthic ecological quality & $H^{\prime}$ & $w$ & AMBI & M-AMBI & BOPA & BENTIX \\
\hline High (no disturbance) & $>4$ & $>0.50$ & $\leq 1.2$ & $>0.77$ & $<0.046$ & $>4.5$ \\
\hline Good (slight disturbance) & $3-4$ & $0.15-0.49$ & $1.2-3.3$ & $0.53-0.77$ & $0.046-0.140$ & $3.5-4.5$ \\
\hline Moderate (moderate disturbance) & $2-3$ & -0.14 to 0.14 & $3.3-5.0$ & $0.38-0.53$ & $0.140-0.194$ & $2.5-3.5$ \\
\hline Poor (serious disturbance) & $1-2$ & -0.49 to -0.15 & $5.0-6$ & $0.20-0.38$ & $0.194-0.268$ & $2.0-2.5$ \\
\hline Bad (extremely serious disturbance) & $<1$ & $\leq 0.50$ & $>6$ & $<0.20$ & $0.268-0.301$ & 0 \\
\hline
\end{tabular}

$H^{\prime}$, Shannon-Wiener diversity index; W, W-statistic value of Abundance-Biomass Comparison curve (ABC curve).

\section{Spatial Patterns}

\section{Spatial Distribution in Winter}

A total of 101 species of macrofauna were recorded during winter cruises. $H^{\prime}$ varied in the range of 3.284-4.406 at 14 sites. The lowest $H^{\prime}$ value was found at site $\mathrm{J} 7$, and the highest value occurred at J10. A slight disturbance occurred at J1, J3, J4, J5, J7, $\mathrm{J} 13$, and J14. The values of the remaining seven sites were greater than 4.0 , and the bioassessment indicated high status.

The range of $W$ values generated by $\mathrm{ABC}$ curve analysis was $0.220-0.430$. The lowest value appeared at site J14 in the east of Jiaozhou Bay, and the highest value appeared at site J11 in the west. As the $W$ value of each site was distributed in the range of $0.15-0.49$, each site was slightly disturbed and the environmental assessment result was good.

The range of AMBI values was 1.589-2.585. The lowest value was observed at site J11, and the highest value was at site J14. All the sampling sites were in good status. The range of M-AMBI was $0.680-0.880$, with the lowest value at site J1 in the northeastern part of Jiaozhou Bay and the highest value at site J10 in the east. There were seven sites with bioassessment as high status, accounting for $50 \%$ of the total sites.

The average values of BOPA in the four seasons were in the range of 0.001-0.036, with the lowest value at site $\mathrm{J} 4$ in the northern part and the highest value at site J1. All sites were of a high status.

The highest BENTIX values occurred at site J4 in the north, whereas the lowest values occurred at site J8 in the middle of the bay. Sites J4, J11, and J12 were of a high status, whereas the rest were of a good status.

All sites in the winter cruise were slightly disturbed or undisturbed, and all types of environmental assessments were in good-high status, with relatively uniform evaluation. As shown in Figure 2, $H^{\prime}$ and M-AMBI showed that the environments in central and southern Jiaozhou Bay were better than those in the north. The AMBI and BNETIX bioassessments were similar, and the benthic environments of the J4 site and southwest were better than other regions.

\section{Spatial Distribution in Spring}

A total of 141 species were identified during the spring cruise. $H^{\prime}$ varied from 1.688 to 4.855 at 14 sites. The lowest value was found at the J12 site in the south, and the bioassessment result indicated a poor status. The highest value was observed at the J10 site in the east. Sites J2, J3, and J5 were of moderate status, whereas sites J1, $\mathrm{J} 4 \mathrm{~J}$ J, and J11 were of good status. Meanwhile, the bioassessment result of J8, J9, J10, J13, and J14 in the central and eastern part indicated a high status.
The range of the $W$ value was $0.069-0.293$. The minimum value appeared at the $\mathrm{J} 12$ site, and the maximum value was observed at the J1 site in the northeastern direction. Sites J2, $\mathrm{J} 3$, and $\mathrm{J} 12$ had moderate disturbances. The environmental assessments at the other sites were rated as good.

The range of AMBI values was 2.001-2.660, with the lowest value at site $\mathrm{J} 11$ and the highest value at site $\mathrm{J} 2$. All sites were rated as having good status. The M-AMBI ranged from 0.510 to 0.910 , with the lowest value located at site J12 and the highest at site J10 in the eastern part. Only site J10 was undisturbed and rated at a high status. Site J12, located in the southern part, had the worst environmental rating, which was consistent with the results of $H^{\prime}$ and $\mathrm{ABC}$ curve. All sites had an environmental rating of good except for site J12.

The BOPA ranged from 0.002 to 0.045 , with the lowest value located at site J2 in the northeast of Jiaozhou Bay and the highest value at site J9. All sites were of a high status.

The range of BENTIX was 2.913-4.439, with the lowest value at the J2 site and the highest value at the $\mathrm{J} 7$ site in the western part of the bay. The benthic environment of the J1 and J2 sites was moderately disturbed, and the other sites were evaluated as having a good status.

During the spring cruise, $H^{\prime}, \mathrm{ABC}$ curve, $\mathrm{AMBI}$, and M-AMBI showed that some sites were moderately and heavily disturbed, mainly at sites J2, J3, and J5 in the north and J12 in the south of Jiaozhou Bay. The central part is slightly disturbed. As shown in Figure 3, various indices indicated that benthic environment of the central part was better than that of the northeastern part in spring, whereas BOPA indicated that the central benthic environment was worse than other parts.

\section{Spatial Distribution in Summer}

A total of 162 species were identified during summer cruises. $H^{\prime}$ ranged from 1.531 to 4.781 , with the lowest value at site J2 in the northeast, which was environmentally assessed as poor status, and the highest value at site J8 in the center. J3 and J13 were environmentally assessed as having a good status, and the rest of the sites were assessed as having a high status.

The $W$ values ranged from 0.075 to 0.447 . The lowest value was at site J2, and the highest was at site J8. Sites J2 and J12 were rated as moderate, and the rest of the sites were rated as good.

The range of AMBI values was 1.747-2.895, with the lowest value at site $\mathrm{J} 7$ and the highest value at site J13, all of which were rated as good. M-AMBI ranged from 0.510 to 0.890 . The lowest value was located at site J2 with an environmental rating of moderate, which is consistent with the worst-rated site in the 

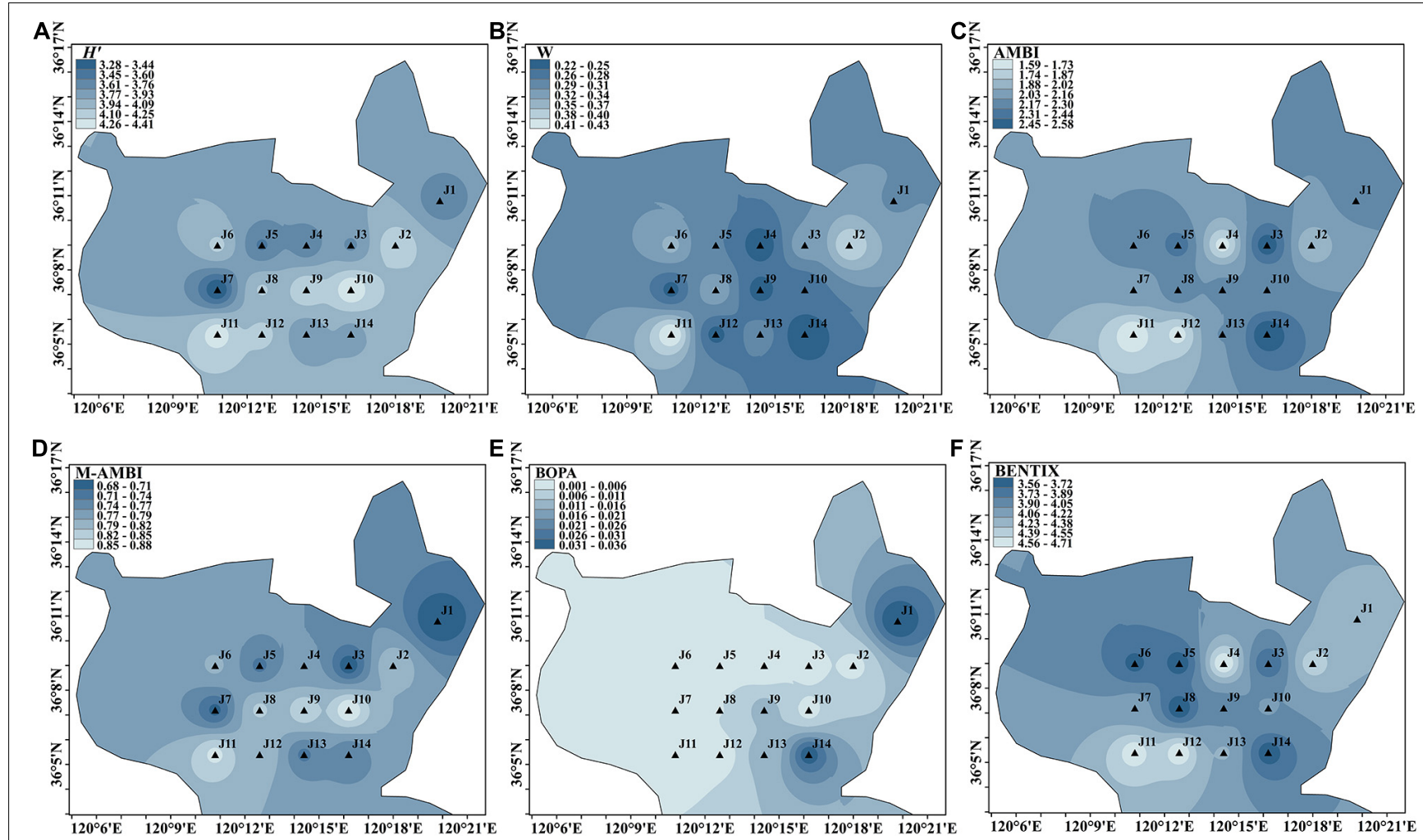

FIGURE 2 | Spatial distribution of environmental assessment in winter cruise in Jiaozhou Bay, $H^{\prime}$ (A), W (B), AMBI (C), M-AMBI (D), BOPA (E), and BENTIX (F).

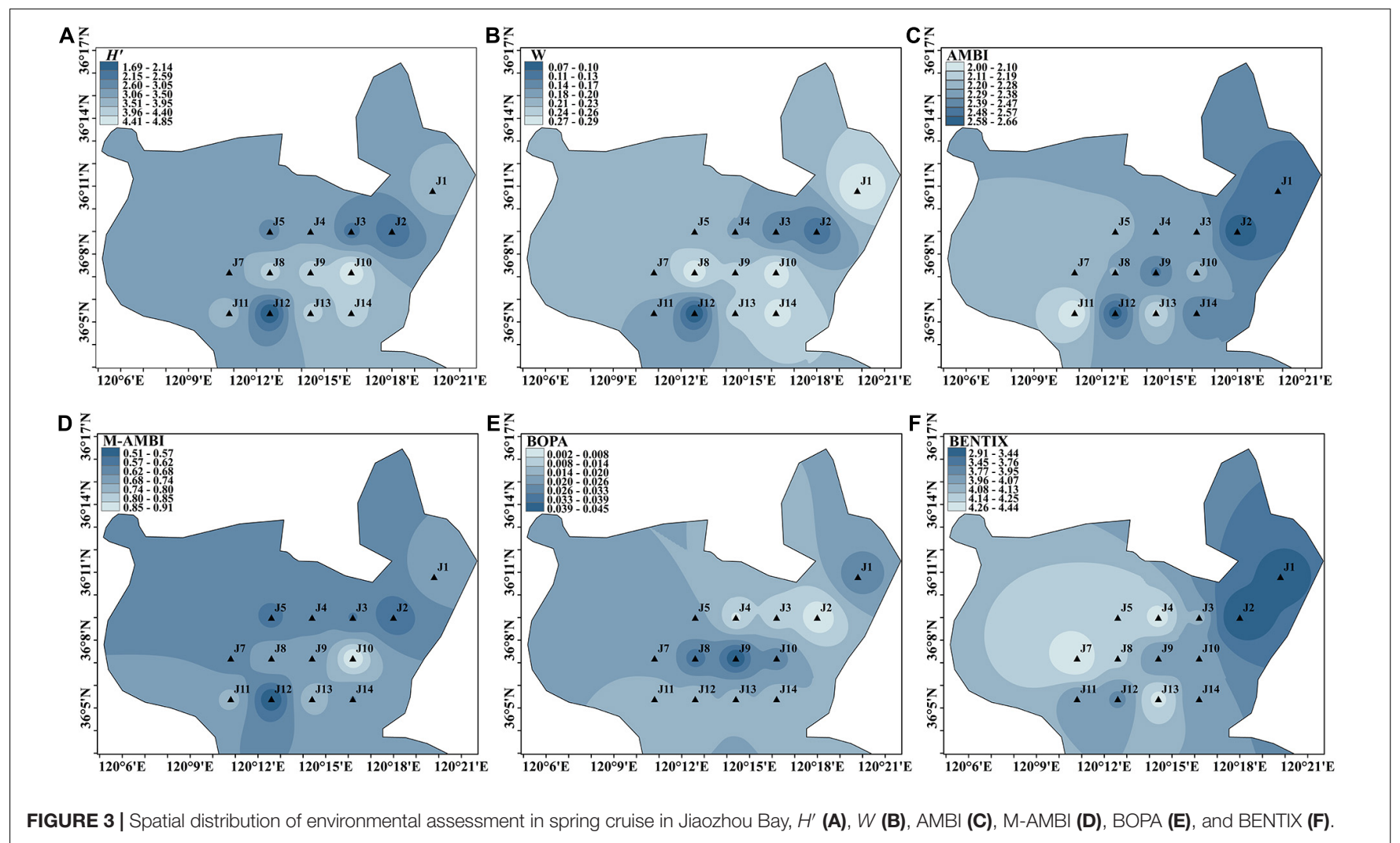


$H^{\prime}, \mathrm{ABC}$ curve, and BENTIX. The central region was assessed as having a high status.

The BOPA range was $0.001-0.063$, with the lowest value at site $\mathrm{J} 2$ and the highest value at site J13. All the sites were assessed as having a high status. Three sites - J5, J11, and J13 - had an environmental rating of good, whereas the rest of the sites had an environmental rating of high.

The BENTIX range was 2.580-5.053, where site J7 was the least disturbed and had the best environmental rating. Site J2 was moderately disturbed and had a moderate environmental rating. The highest and lowest values are consistent with those of the summer cruise. The J3, J7, J12, and J14 sites had a high environmental rating, and the rest of the sites had a good environmental rating.

As shown in Figure 4, during the summer cruise, different indices generally rated the benthic environment as high. However, various indices showed moderate to heavy disturbance at site $\mathrm{J} 2$, with only BOPA showing no disturbance at this site. Some of the sites in the southern part of Jiaozhou Bay were also lightly disturbed, which made the benthic environment worse than that of the central region.

\section{Spatial Distribution in Autumn}

A total of 144 species were identified during autumn cruise. $H^{\prime}$ ranged from 3.607 to 4.753 , with the lowest value at site J5 and the highest value at site J9. Sites J1, J2, J4, J5, J11, and J14 were assessed as having a good status, whereas the rest were assessed as having a high status.
The $W$ values ranged from 0.045 to 0.349 . The lowest value was observed at site J5, and the highest was at site J12. Meanwhile, sites J5 and J14 were rated as moderate, and the rest of the sites were rated as good.

The range of AMBI values was 2.345-3.285, with the lowest value at site $\mathrm{J11}$ and the highest value at site J1. All sites had an environmental rating of good. The M-AMBI ranged from 0.670 to 0.840 , with the lowest values located at site $\mathrm{J} 1$ and the highest values at sites J2, J8, and J9. The environmental assessment was high, except for sites J1, J3, J4, J5, and J14.

The BOPA range was 0.034-0.101, with the lowest value at site J2 and the highest value at site J1. Sites J2, J3, and J9 were rated as high, and the rest of the sites were rated as good.

The BENTIX range was 2.629-4.390, with the lowest value at site $\mathrm{J} 1$ and the highest value at site J11. Seven sites had moderate contamination, namely $\mathrm{J} 1, \mathrm{~J} 2, \mathrm{~J} 3, \mathrm{~J} 4, \mathrm{~J} 5, \mathrm{~J} 8$, and $\mathrm{J} 14$, whereas the rest of the sites had an environmental rating of good.

The BENTIX value was poor for the autumn cruise, with over $50 \%$ of the sites being moderately disturbed, mostly in the northern part of Jiaozhou Bay. As shown in Figure 5, multiple indices showed that site J1 was the most disturbed, followed by site J5. Overall, the environmental assessment of the central and southern parts of Jiaozhou Bay was generally better than that of the northern part.

\section{Season Patterns}

Among the four cruises of macrofaunal surveys in 2014, the largest number of species (162 species) were surveyed in

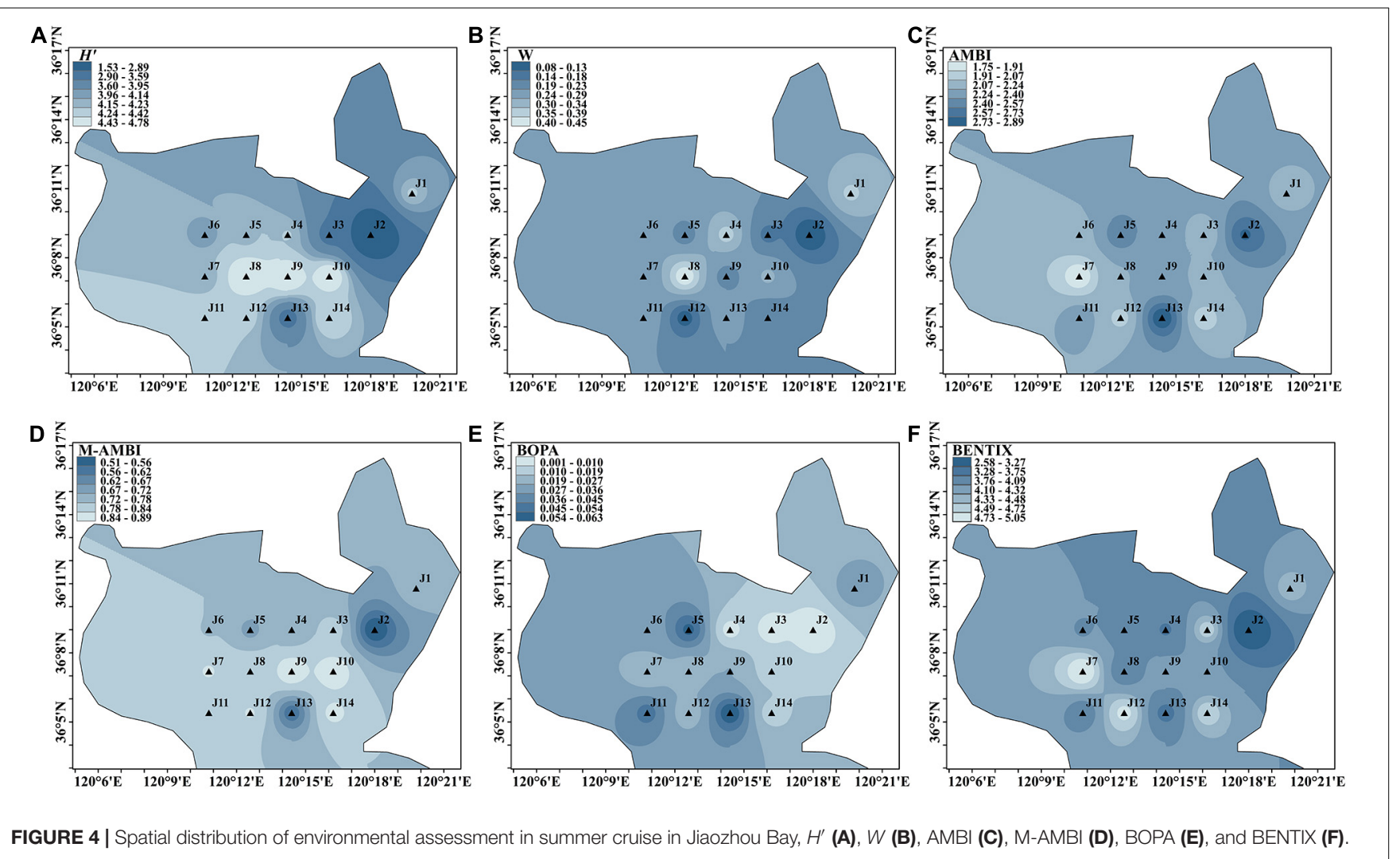



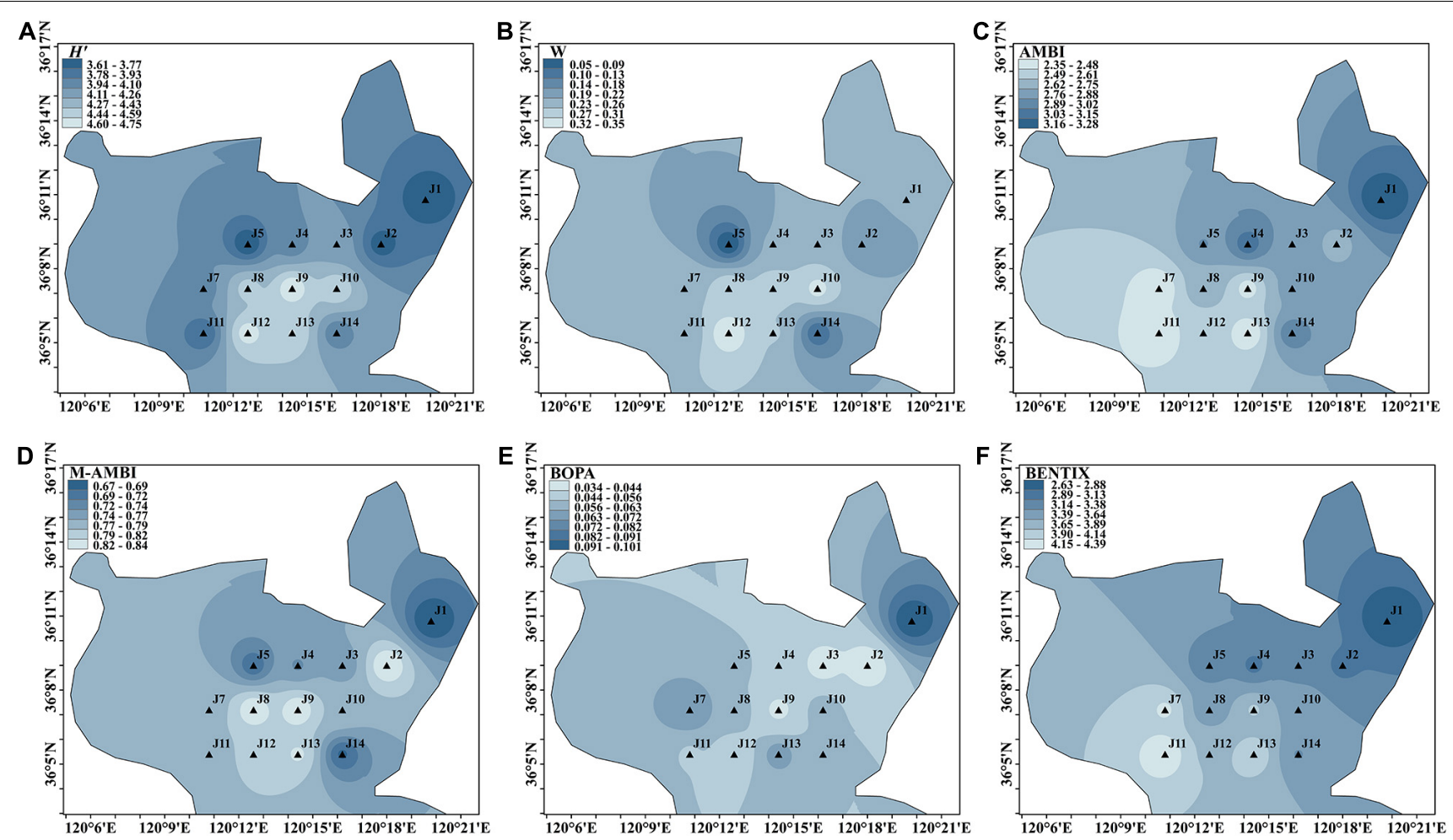

FIGURE 5 | Spatial distribution of environmental assessment in autumn cruise in Jiaozhou Bay, $H^{\prime}$ (A), W (B), AMBI (C), M-AMBI (D), BOPA (E), and BENTIX (F).

the summer, with an average abundance of 2708.93 ind. $/ \mathrm{m}^{2}$. The number of species investigated during the winter cruise was the lowest (101 species), with an average abundance of $1199.64 \mathrm{ind} . / \mathrm{m}^{2}$. The number of species surveyed in the spring cruise (141 species) and autumn cruise (144 species) were similar, with average abundances of 2476.92 ind. $/ \mathrm{m}^{2}$ and 3542.69 ind. $/ \mathrm{m}^{2}$, respectively. In terms of biomass, the results of the survey were winter $\left(164.62 \mathrm{~g} / \mathrm{m}^{2}\right)<$ spring $\left(524.94 \mathrm{~g} / \mathrm{m}^{2}\right)<$ summer $\left(572.08 \mathrm{~g} / \mathrm{m}^{2}\right)<$ autumn $\left(814.18 \mathrm{~g} / \mathrm{m}^{2}\right)$. Ruditapes philippinarum was the dominant species in the biomass.

As shown in Figure 6, in terms of $H^{\prime}$, the environmental assessment of the spring cruise was the most unstable, with a wide range of variation. The environmental quality of the autumn cruise was significantly higher than that of the spring cruise. With regard to the $A B C$ curve, the winter cruise had better environmental quality, but there was no significant difference between the $W$ values of the four cruises. AMBI rated the benthic environment as good in all four seasons, but the environmental quality of the autumn cruise was still significantly lower than that of the other cruises. With regard to the M-AMBI value, the environmental quality of the spring cruise was significantly lower than that of the other cruises. Only one site on the spring cruise reached a high standard, which was lower than that of the other cruises. In terms of BOPA, the environmental quality of the autumn cruise was significantly lower than that of the other cruises whereas the environmental quality of all sites during the winter and spring cruises was high; only three sites on the summer cruise were rated as good. For BENTIX, the environmental quality of the autumn cruise was significantly lower than that of the other cruises, with $53.8 \%$ of sites rated as moderate.

As shown in Figure 6, $H^{\prime}, W$, and M-AMBI all showed the worst environmental assessment for the spring cruise. BOPA, AMBI, and BENTIX showed the worst environmental assessment for the autumn cruise. A one-way ANOVA showed that there was a significant difference between the autumn and spring cruises of $H^{\prime}$. There was no significant difference between the $W$ values of the four cruises. M-AMBI of the autumn cruise was significantly different from that of the other cruises. Among AMBI, BOPA, and BENTIX, the bioassessment of autumn cruises was significantly different from that of the other cruises.

\section{Limitations of the Biotic Indices Based on AZTI's Marine Biotic Index Species List}

BOPA, AMBI, M-AMBI, and BENTIX were calculated based on taxon sensitivity classification. BOPA is based on the proportion of polychetes and amphipods, and the other three are referenced to the AMBI species list. The calculation and analysis of the index will be better understood by comparing the composition of EGIEGV groups in different sites.

Based on the AMBI species list, the distribution of different biological groups at each sampling site was analyzed. As shown in Figure 7, the proportions of the EGII and EGIII groups were similar and high in most sites. In contrast, the 

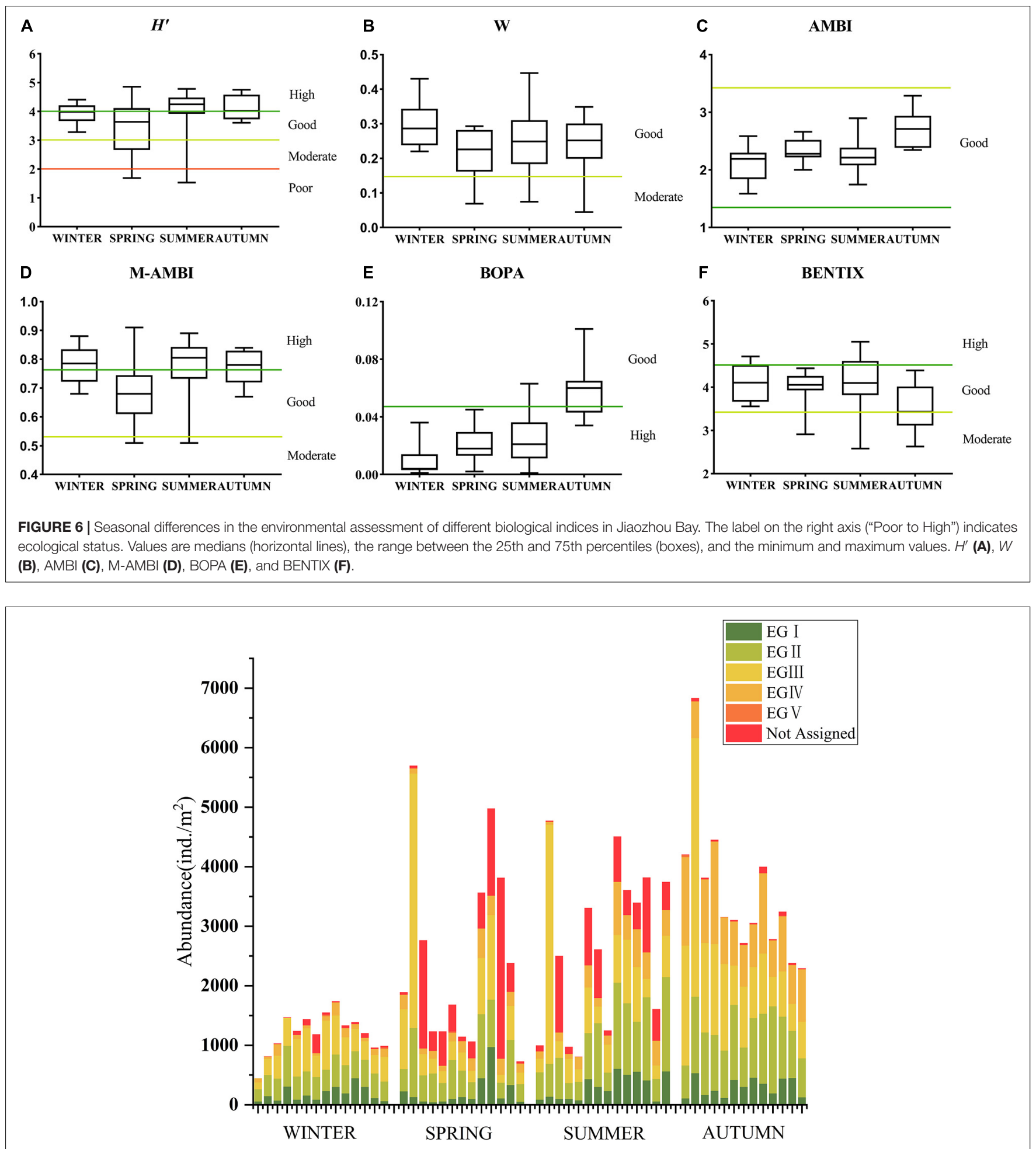

FIGURE 7 | Abundance of groups at different sites of four cruises based on the AMBI species list in Jiaozhou Bay. EGI-EGV: ecological groups I-V based on AMBI species list. Not assigned: the unassigned species based on AMBI species list.

proportion of species at the EGIV and EGV groups was extremely low. A significantly higher proportion of the EGIII group occurred at site $\mathrm{J} 2$ during the spring, summer, and autumn cruises. $R$. philippinarum was the dominant species at this site. The species abundance of unassigned organisms in the spring and summer cruises was relatively high, especially at site 
J12 (spring). Hemileucon bidentatus was the main unassigned species, and its genus (Hemileucon sp.) was not assigned to the AMBI species list.

\section{Correlation Analysis of Biological Index}

The correlation analysis results of each biological index and environmental parameters (Table 2) showed that $H^{\prime}$ had a significant positive correlation with $\mathrm{pH}$, and $W$ had a significant positive correlation with sediment organic matter content. AMBI was significantly correlated with bottom water salinity, $\mathrm{pH}$, Chl- $a$, and sediment organic matter content. M-AMBI had a significant positive correlation with $\mathrm{pH}$. BOPA had a highly significant correlation with bottom water salinity. In this study, BENTIX showed no correlation with environmental parameters. Water depth, temperature, Pha content, and median grain size also did not have a significant impact on the biological index.

Correlation analysis results between the six indices (Table 3) showed that $H^{\prime}$ and $W$ values, M-AMBI, and BENTIX had a significant positive correlation; $W$ had a highly significant positive correlation with $\mathrm{M}-\mathrm{AMBI}$, and a significant negative correlation with AMBI. AMBI had a highly significant negative correlation with M-AMBI and BENTIX, and a highly significant positive correlation with BOPA; and BENTIX had a highly significant positive correlation with $\mathrm{M}-\mathrm{AMBI}$ and BOPA. Overall, M-AMBI had the highest correlation with the other indices. Among them, it had an extremely significant correlation with the four indices and only had no significant correlation with BOPA.

\section{DISCUSSION}

\section{Evaluation of Different Biological Indices}

Biological monitoring can comprehensively reflect the interaction between various environmental pollution factors and can continuously monitor ecological health (Wang et al., 2010; Markert et al., 2013). The results of the multiple biotic assessment methods showed that Jiaozhou Bay had a good benthic ecological quality status, which was consistent with the results of other studies (Yang et al., 2021; Yin et al., 2021).

Shellfish aquaculture activities have expanded in the bay since the 1980s, making the region an important shellfish production base in China (Gu et al., 2021b). R. philippinarum has been cultivated in Jiaozhou Bay since 2003 (Fan and Liu, 2016), becoming the dominant species of macrofauna until now (Wang et al., 2011). For nearly 150 years, Jiaozhou Bay area has been reduced by $235.41 \mathrm{~km}^{2}$ during 1863-2012 (Ma et al., 2014), inevitably causing a sharp decline in water exchangeability in the bay. Industrial and domestic sources along the north coast led to significant increases in $\mathrm{N}$ and $\mathrm{P}$ in the water (Sun et al., 2011; Gao et al., 2018), but the diffusion and attenuation of these nutrients were impeded by the descending hydrodynamic force and the deterioration of water quality in the semi-enclosed bay (Zhang et al., 2021). Spatially, Qingdao ports (Qingdao Port and Huangdao Port) are mainly located in the eastern and western waters of Jiaozhou Bay, and pollutants brought by wharf construction and a large number of ships make the concentrations of $\mathrm{Cu}, \mathrm{Pb}, \mathrm{Zn}, \mathrm{Hg}$, and $\mathrm{Cr}$ higher in the east of Jiaozhou Bay and the western part of the bay mouth ( $\mathrm{He}$ et al., 2013). In addition, industrial wastewater mainly flowed into the Bay from river mouth, and quantity of pollutant discharge rapidly from about $7.0 \times 10^{7} \mathrm{t} / \mathrm{a}$ in the $1980 \mathrm{~s}$ to $1.0 \times 10^{8} \mathrm{t} / \mathrm{a}$ in the 1990s, and then maintained at about $9.8 \times 10^{7} \mathrm{t} / \mathrm{a}(\mathrm{He}$ et al., 2013). The estuaries of Dagu River, Baisha River, Licun River, and Haibo River are mainly distributed in the northern and eastern part of Jiaozhou Bay. Among them, COD emissions of Dagu River accounted for about $40.4 \%$ of Jiaozhou Bay. The Haibo River located in the east of the bay mouth had the largest discharge of inorganic nitrogen and phosphate, accounting for more than $35 \%$ of the total discharge of Jiaozhou Bay, followed by the Dagu River and Licun River (Zhang and Sun, 2007). In this study, the northeastern and southern parts of the bay were moderately disturbed by varying degrees, particularly at sites J2 and J12. Site J2 was in a mariculture area with an extremely high abundance of $R$. philippinarum, while the abundance of this species was low at other sites, which may cause the poor benthic environmental quality of the site J2 and J12 according to the evaluation. At the same time, it is located in the Licun estuary, and the river carries land-based pollutants into the sea, which may have an impact on the benthic environment. Studies have shown that the Licun and Dagu estuaries were enriched in $\mathrm{Cr}, \mathrm{Ni}$, and $\mathrm{Cu}$ heavy metals (Xiao et al., 2017), and the benthic environment of the northern waters of Jiaozhou Bay and Licun estuary were more seriously disturbed (Cui et al., 2020; Yang et al., 2021), which is consistent with the results

TABLE 2 | Correlation analysis among biotic indices and environmental variables in Jiaozhou Bay.

\begin{tabular}{|c|c|c|c|c|c|c|c|c|c|}
\hline & D & $\mathbf{T}$ & Sal. & $\mathrm{pH}$ & Chl-a & Pha & $\mathrm{W} / \%$ & OM/\% & $\mathrm{Md} / \mathrm{mm}$ \\
\hline$H^{\prime}$ & 0.230 & -0.038 & -0.119 & $0.276^{\star}$ & 0.075 & 0.175 & 0.023 & 0.000 & 0.047 \\
\hline$W$ & -0.060 & -0.204 & 0.009 & 0.170 & 0.225 & 0.161 & -0.080 & $0.303^{\star}$ & -0.006 \\
\hline AMBI & -0.008 & 0.032 & $-0.278^{\star}$ & $-0.288^{\star}$ & $-0.283^{*}$ & 0.033 & 0.115 & $-0.299^{\star}$ & -0.204 \\
\hline M-AMBI & 0.128 & -0.108 & 0.006 & $0.345^{\star}$ & 0.087 & 0.143 & -0.065 & 0.099 & 0.216 \\
\hline BOPA & -0.093 & -0.085 & $-0.349^{\star \star}$ & -0.235 & -0.067 & 0.198 & 0.262 & -0.405 & -0.167 \\
\hline BENTIX & 0.174 & 0.083 & 0.146 & 0.148 & 0.234 & -0.024 & 0.043 & 0.120 & 0.100 \\
\hline
\end{tabular}

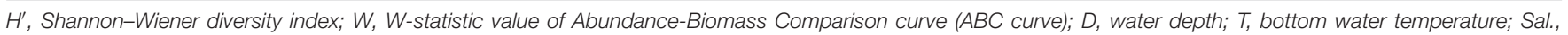
bottom water salinity; $W$, sediment water content; OM, sediment organic matter content; Md, median grain size.

**Significant at 0.01 level; *significant at 0.05 level. 
TABLE 3 | Results of correlation analysis among six biotic indices.

\begin{tabular}{lccccc}
\hline Biotic index & $\boldsymbol{H}^{\prime}$ & $\boldsymbol{W}$ & AMBI & M-AMBI & BOPA \\
\hline$W$ & $0.618^{\star \star}$ & & & & \\
AMBI & -0.206 & $-0.296^{\star}$ & & & \\
M-AMBI & $0.857^{\star \star}$ & $0.462^{\star *}$ & $-0.430^{\star *}$ & & \\
BOPA & 0.255 & -0.073 & $0.627^{\star *}$ & -0.008 & \\
BENTIX & $0.289^{\star}$ & 0.208 & $-0.862^{\star *}$ & $0.380^{\star \star}$ & $-0.342^{\star *}$
\end{tabular}

$H^{\prime}$, Shannon-Wiener diversity index; W, W-statistic value of Abundance-Biomass Comparison curve ( $A B C$ curve).

${ }^{* *}$ Significant at 0.01 level; *significant at 0.05 level.

of this study. The poor benthic environment in the northern areas may also be related to the construction of the Jiaozhou Bay Bridge. Site J12, located in the southern part, showed severe and moderate disturbance in the environmental assessment in spring and summer, which may have been caused by the high abundance of $H$. bidentatus in spring $\left(2980 \mathrm{ind} . / \mathrm{m}^{2}\right)$ and summer (1140 ind. $/ \mathrm{m}^{2}$ ), accounting for $78.11 \%$ and $29.84 \%$ of the total abundance, respectively, which had some impact on the environmental assessment. All the results of the six biotic indices of the central sites (J7, J9, and J10) were in good high status, and the evaluation results were consistent, showing that the benthic environment in the central site was relatively stable, and the living environment of macrofauna was not affected by strong human activities.

Since the 1980s, the intertidal area of Jiaozhou Bay has been decreasing due to the influence of human activities, such as the reclamation of the sea and the development of saltern (Lei et al., 2013). The water exchange capacity of each region has gradually reduced, resulting in serious eutrophication of seawater (Yang et al., 2018; Yuan et al., 2020). At the beginning of the 21st century, with the implementation of a series of protection measures and the abandonment of salt pans and aquaculture ponds (Yang et al., 2018), the water area of Jiaozhou Bay gradually rebounded, while environmental pollution was also reduced (Lei et al., 2013; Gu et al., 2021a; Yang et al., 2021). In recent years, the number of macrobenthic species has generally shown an increasing trend (Yang et al., 2021), and the ecosystem functioning has remained stable. Temporally, the benthic environment was less favorable in spring and autumn than in summer and winter. The higher abundance of $R$. philippinarum and $H$. bidentatus at J2, J3, J11, and $\mathrm{J} 12$ in the spring cruise was probably the main factor that pulled down the overall benthic environment assessment. In the autumn cruise, the mean abundance of Mediomastus sp. was relatively high, with an average abundance of 507.69 ind. $/ \mathrm{m}^{2}$. At the same time, Mediomastus sp. belonged to the EGIII class of pollution-tolerant species. Therefore, the indices based on the benthic sensitivity classification showed that the environmental assessment of the autumn cruise was poor.

\section{Effects of Environmental Factors on Macrofauna}

Changes in habitat directly affect the species composition and community structure of macroinvertebrates. Many studies have shown that the spatial distribution of macrofauna is closely related to water temperature, water depth, hydrodynamic conditions, dissolved oxygen content, and sediment types (Mancinelli et al., 1998; Ysebaert and Herman, 2002; Como and Magni, 2009; Yang et al., 2021). For example, in the survey conducted by Quan et al. (2020a), temperature, nutrients, and sediment types were the environmental factors that mainly affected the distribution characteristics of macrofauna. At the same time, heavy metal pollution can accumulate in the viscera and tissues of benthic organisms, hindering their growth and reproduction (Solà and Prat, 2006). High levels of total phosphorus and nitrogen can lead to the loss of macrobenthic species and an increase in the biomass of tolerant species (Cai et al., 2014). Eutrophication is also associated with ocean surface hypoxia and seawater acidification, which can increase the sensitivity of coastal zone seawater to ocean acidification (Lv et al., 2016; Gao et al., 2020).

The effect of temperature on macrofaunal diversity was also significant in this study, with winter macrofaunal diversity being significantly lower than in other seasons. A number of investigations have concluded that macrofaunal abundance has a highly significant positive correlation with bottom temperature (Shojaei et al., 2015; Neumann et al., 2021), especially in semienclosed bays, which may be related to the drastic changes in bottom temperature (Yang et al., 2021). Multi-biotic indices were significantly or highly significantly correlated with $\mathrm{pH}$, organic matter, sediment salinity, and Chl- $a$ content, suggesting that the marine benthic environment is related to $\mathrm{pH}$, and nutrients, which is similar to other studies (Oleszczuk et al., 2021; Toussaint et al., 2021). In the study by Neumann et al. (2021), bioturbation and temperature had the highest explanatory power to explain the substantial seasonal variability in observed oxygen and nutrients. The total organic matter content is an important environmental variable for anoxic mineralization (Toussaint et al., 2021). Low oxygen conditions can change predator-prey relationships and destroy benthic habitats (Briggs et al., 2017).

\section{Comparisons Among Different Biotic Indices}

Because of the complexity of the marine ecosystem and the difference in reference values of different evaluation indices, different evaluation indices usually give different evaluation results in the same region (Medeiros et al., 2012; Wu et al., 2013). In this study, the benthos sensitivity classification indices (AMBI, BOPA, and BENTIX), the benthic biodiversity indices ( $H^{\prime}$ and $\mathrm{ABC}$ curve), and the composite index (M-AMBI) combined with multiple indices were mutually calibrated. $H^{\prime}$ and $\mathrm{ABC}$ curve rely on abundance and biomass relationships and do not consider taxon characteristics. AMBI, M-AMBI, and BENTIX are three types of indices needed to classify the species, which is a tedious and time-consuming operation (dela-Ossa-Carretero et al., 2009). In particular, some endemic species are not included in the classification list; therefore, it is necessary to find the same genus for classification judgment, which has certain subjectivity. For example, in this 
study, the species of $H$. bidentatus were highly abundant, but they were not assigned to AMBI and M-AMBI. In addition, AMBI presents some limitations when applied to semi-enclosed systems. The relative frequencies of opportunistic polychetes and amphipods were used for BOPA environmental assessment. Opportunistic polychetes are tolerant to organic-rich sediments, while amphipods are sensitive to changes in the organic matter content (de-la-Ossa-Carretero et al., 2009). The complexity of the classification operation was reduced in this index, but the influence of other organisms on the benthic environment was not considered. Some studies have pointed out that under low disturbance conditions, amphipods are susceptible to other environmental factors, such as temperature, and low disturbance levels cannot cause polychete opportunistic species to become the dominant species (Wang et al., 2017). Therefore, the BOPA is not suitable for evaluating environmental quality when the disturbance is relatively light. BENTIX is considered an ecologically relevant biological index, which is easier to operate than AMBI and M-AMBI and has been successfully applied to areas of organic matter pollution, oil spills, and heavy metal pollution (Simboura and Zenetos, 2002; Zenetos et al., 2004; Simboura et al., 2007). It is more sensitive to the increase in organic matter content in sediments than AMBI (Caglar and Albayrak, 2012), but all opportunistic taxonomic groups (AMBIEG IV and V) and sensitive taxonomic groups (AMBI-EG III) are given the same proportion in the evaluation; therefore, the ecological state is easily underestimated. At the same time, unassigned organisms remain neglected because of their reliance on the AMBI classification criteria.

In the present study, the abundance of $R$. philippinarum and $H$. bidentatus was extremely high at some sites. These sites (J2 and J12) were evaluated as moderately or severely disturbed according to the $H^{\prime}$ and $\mathrm{ABC}$ curve, which differed from the results of other indices. It is obviously unreasonable to conclude that the benthic environment was severely disturbed by abundance and biomass alone in mariculture area (Cai et al., 2016), which verifies the first hypothesis. Therefore, it is recommended to avoid using the ABC curve alone for environmental evaluation in aquaculture areas. The disturbance caused by artificial culture for environmental evaluation should be fully considered. M-AMBI had a highly significant correlation with the other indices (expect BOPA) $(p<0.01)$. Compared with other indices in this study, M-AMBI is more accurate, which supports the second hypothesis. When using AMBI and $\mathrm{M}-\mathrm{AMBI}$, the abundance proportion of unassigned species should be fully considered.

\section{CONCLUSION}

Long-term monitoring and evaluation play an important role in the healthy development of benthic ecosystems, and the biological index of benthic ecological characteristics is generally not universally adopted. Therefore, the use of a single index for environmental assessment is one-sided and unstable, and the combination of various methods is more likely to obtain the overall environmental pollution in the survey areas. When the abundance of non-polychete opportunistic species and amphipods was high, BENTIX was better than BOPA in evaluating environmental quality. In mariculture areas, the extremely high abundance of a single species brings high biomass, and it is recommended to use the $\mathrm{ABC}$ curve with caution. Therefore, in the construction of aquatic ecological evaluation based on macrofauna, we recommend using the biotic indices with caution and, whenever possible, calculating several to reduce potential biases in the quality assessment. The classification of species tolerance should be integrated to weaken the objective difference between the evaluation methods of biological evaluation indices to obtain more comprehensive and accurate results for aquatic ecological evaluation.

\section{DATA AVAILABILITY STATEMENT}

The original contributions presented in the study are included in the article/Supplementary Material, further inquiries can be directed to the corresponding author.

\section{AUTHOR CONTRIBUTIONS}

$\mathrm{XLu}, \mathrm{JX}, \mathrm{ZX}$, and XLiu contributed to the collection of samples, conception, design, collation, analysis of data, and preparation of the manuscript. XLu collated and analyzed the data and wrote the draft of the manuscript. JX contributed to the data reanalysis and the writing, revision of the manuscript. ZX contributed to the collection and identification of macrofauna and the collection of sediment samples. XLiu contributed to the experiment design, source acquisition, manuscript writing, revision, and approved the submitted version. All authors contributed to the article and approved the submitted version.

\section{FUNDING}

This study was jointly supported by the Fundamental Research Funds for the Central Universities (No. 201964024), Key Laboratory of Marine Ecology and Environmental Science and Engineering, State Oceanic Administration, China (No. MESE2019-08), and the Biodiversity Investigation, Observation and Assessment Program (2019-2023) of the Ministry of Ecology and Environment of China.

\section{ACKNOWLEDGMENTS}

We appreciate the help of many members of the Laboratory of Benthos during field sampling, laboratory analysis, and manuscript preparation.

\section{SUPPLEMENTARY MATERIAL}

The Supplementary Material for this article can be found online at: https://www.frontiersin.org/articles/10.3389/fmars.2021. 734710/full\#supplementary-material 


\section{REFERENCES}

Briggs, K. B., Craig, J. K., Shivarudrappa, S., and Richards, T. M. (2017). Macrobenthos and megabenthos responses to long-term, large-scale hypoxia on the Louisiana continental shelf. Mar. Environ. Res. 123, 38-52. doi: 10.1016/ j.marenvres.2016.11.008

Caglar, S., and Albayrak, S. (2012). Assessment of ecological quality status of Küçükçekmece Bay (Marmara Sea) by applying BENTIX, AMBI, BOPA and BO2A biotic indexes. Mediterr. Mar. Sci. 13, 198-207. doi: 10.12681/ mms.299

Cai, W., Borja, A., Liu, L. S., Meng, W., Muxika, I., and Rodríguez, J. G. (2014). Assessing benthic health under multiple human pressures in Bohai Bay (China), using density and biomass in calculating AMBI and M-AMBI. Marine Ecology. 35, 180-192. doi: 10.1111/maec.12067

Cai, W. Q., Liu, J., Zhou, J., Xia, Y., and Liu, L. S. (2016). Composition of macrozoobenthos functional feeding groups and assessment of ecological quality using the feeding evenness index calculated from biomass data. Biodivers. Sci. 24, 1045-1055. doi: 10.17520/biods.2016062

Como, S., and Magni, P. (2009). Temporal changes of a macrobenthic assemblage in harsh lagoon sediments. Estuar. Coast. Shelf Sci. 83, 638-646. doi: 10.1016/j. ecss.2009.05.024

Cui, W. Y., Yang, X. J., Zhang, M. S., Chen, C., and Yu, Z. S. (2020). Diversity and community structure of the Macrobenthos in Jiaozhou Bay in Spring. Mar. Sci. 44, 101-109. doi: 10.11759/hykx20191118001

de-la-Ossa-Carretero, J. A., del-Pilar-Ruso, Y., Giménez-Casalduero, F., and Sánchez-Lizaso, J. L. (2009). Testing BOPA index in sewage affected soft-bottom communities in the north-western Mediterranean. Mar. Poll. Bull. 58, 332-340. doi: 10.1016/j.marpolbul.2008.10.017

Egres, A. G., Hatje, V., Miranda, D. A., Gallucci, F., and Barros, F. (2019) Functional response of tropical estuarine benthic assemblages to perturbation by Polycyclic Aromatic Hydrocarbons. Ecol. Indic. 96, 229-240. doi: 10.1016/j. ecolind.2018.08.062

Eleftherious, A., and McIntyre, A. (2013). Methods for the Study of Marine Benthos. United States: Blackwell Publishing.

Fan, Y., and Liu, X. S. (2016). Seasonl distribution and resource assessment of Manila Clam (Ruditapes philippinarum) in Jiaozhou Bay, China. Period. Ocean Univ. China. 46, 70-74. doi: 10.16441/j.cnki.hdxb.20150338

Feng, M., Han, Q. X., and Yan, R. X. (2021). Community structure and functional traits of the rocky intertidal macrobenthos in Jiushan Islands. Chin. J. Ecol. 40, 1469-1477. doi: 10.13292/j.1000-4890.202105.007

Fu, F. F., Li, C. H., and Xu, S. N. (2018). Analysis of the characteristics of the macrobenthic community of Jiaozhou Bay in winter. J. Fish. Sci. China. 25, 159-168. doi: 10.3724/SP.J.1118.2018.17072

Gao, C. C., Yu, F. L., Chen, J. X., Huang, Z. Q., Jiang, Y. W., and Zhuang, Z. X. (2021). Anthropogenic impact on the organic carbon sources, transport, and distribution in a subtropical semi-enclosed bay. Sci. Total Environ. 767:145047. doi: 10.1016/j.scitotenv.2021.145047

Gao, G. D., Wang, X. H., Bao, X. W., Song, D. H., Lin, X. P., and Qiao, L. L. (2018). The impacts of land reclamation on suspended-sediment dynamics in Jiaozhou Bay, Qingdao, China. Estuar. Coast. Shelf Sci. 206, 61-75. doi: 10.1016/j.ecss. 2017.01.012

Gao, K. S., Gao, G., Wang, Y. J., and Dupont, S. (2020). Impacts of ocean acidification under multiple stressors on typical organisms and ecological processes. Mar. Life Sci. Technol. 2, 279-291. doi: 10.1007/s42995-020-00048-w

Graf, G., and Rosenberg, R. (1997). Bioresuspension and biodeposition: a review. J. Mar. Syst. 11, 269-278. doi: 10.1016/S0924-7963(96)00126-1

Gu, X., Lin, C. Y., Xin, M., Ouyang, W., He, M. C., Liu, X. T., et al. (2021a). Baseline, enrichment, and ecological risk of arsenic and antimony in the Jiaozhou Bay, a semi-enclosed bay of the Yellow Sea, China. Mar. Poll. Bull. 168:112431. doi: 10.1016/j.marpolbul.2021.112431

Gu, X., Xu, L., Wang, Z. X., Ming, X., Dang, P., Ouyang, W., et al. (2021b). Assessment of cadmium pollution and subsequent ecological and health risks in Jiaozhou Bay of the Yellow Sea. Sci. Total Environ. 774:145016. doi: 10.1016/ j.scitotenv.2021.145016

He, S. F., Li, G. X., and Shi, J. H. (2013). Distribution of heavy metals in surficial sediments of Jiaozhou bay and its influencing factors. Mar. Geol. Front. 29, 41-48. doi: 10.16028/j.1009-2722.2013.04.005
Huang, D. Y., Wang, J. J., Chen, G. L., and Zheng, X. Q. (2021). Community structure and ecological warning of reef-associated fish and macrobenthos in the Yalong Bay. Chin. J. Ecol. 40, 412-426.

Huang, L. M., Huang, X. P., Song, X. Y., Tan, Y. H., and Wang, H. K. (2003). Frequent occurrence areas of red tide and its ecological characteristics in Chinese coastal waters. Ecol. Sci. 22, 252-256. doi: 10.3969/j.issn.1008-8873. 2003.03.013

Ji, X., Xu, R., Liu, C. C., Qin, Y. T., Yuan, Y. M., Xu, J. C., et al. (2016). Assessment of macrobenthic community health in the coastal waters of Qidong. Mar. Fishe. 38, 348-363. doi: 10.13233/j.cnki.mar.fish.2016.04.002

Lei, N., Hu, X. Y., and Zhou, X. H. (2013). Evolution process and ecological effect analysis of reclamation in Jiaozhou Bay. Mar. Environ. Sci. 32, 506-509.

Li, B. Q., Jiang, S. Y., Lv, J. Z., Yan, L., Liu, C. Y., Li, X. J., et al. (2020). Species composition and long-term variation of macrobenthos in intertidal zone and offshore areas of the Yellow River Delta. Biodivers. Sci. 28, 1511-1522. doi: 10.17520/biods.2020164

Lim, D., Jung, H. S., Kim, K. T., Shin, H. H., and Jung, S. W. (2012). Sedimentary records of metal contamination and eutrophication in Jinhae-Masan Bay, Korea. Mar. Poll. Bull. 64, 2542-2548.

Liu, L., Zhou, J., Zheng, B., Cai, W., Lin, K., and Tang, J. (2013). Temporal and spatial distribution of red tide outbreaks in the Yangtze River Estuary and adjacent waters, China. Mar. Poll. Bull. 72, 213-221. doi: 10.1016/j.marpolbul. 2013.04.002

Lv, Y. L., Yuan, J. J., Liu, Q. F., Zhang, Y. Q., Lv, X. T., and Su, C. (2016). Impacts of land-based human activities on coastal and offshore marine ecosystems. Acta Ecol. Sin. 36, 1183-1191. doi: 10.5846/stxb201511182334

Ma, L. J., Yang, X. G., Qi, Y. L., Liu, Y. X., and Zhang, J. Z. (2014). Oceanic area change and contributing factor of Jiaozhou Bay. Sci. Geogr. Sin. 34, 365-369. doi: 10.13249/j.cnki.sgs.2014.03.365

Mancinelli, G., Fazi, S., and Rossi, L. (1998). Sediment structural properties mediating dominant feeding types patterns in soft-bottom macrobenthos of the Northern Adriatic Sea. Hydrobiologia 367, 211-222. doi: 10.1023/A: 1003292519784

Markert, B., Wang, M. E., Wünschmann, S., and Chen, W. P. (2013). Bioindicators and biomonitors in environmental quality assessment. Acta Ecol. Sin. 33, 33-44. doi: $10.5846 /$ stxb201106300977

Medeiros, J. P., Chaves, M. L., Silva, G., Azeda, C., Costa, J. L., Marques, J. C., et al. (2012). Benthic condition in low salinity areas of the Mira estuary (Portugal): Lessons learnt from freshwater and marine assessment tools. Ecol. Indicat. 19, 79-88. doi: 10.1016/j.ecolind.2011.09.008

Melet, A., Teatini, P., Cozannet, G. L., Jamet, C., Conversi, A., Benveniste, J., et al. (2020). Earth observations for monitoring marine coastal hazards and their drivers. Surv. Geophys. 41, 1489-1534. doi: 10.1007/s10712-020-09594-5

Neumann, A., Beusekom, J. E. E., Eisele, A., Emeis, K. C., Friedrich, J., Krncke, I., et al. (2021). Macrofauna as a major driver of bentho-pelagic exchange in the southern North Sea. Limnol. Oceanogr. 66, 2203-2217. doi: 10.1002/lno.1 1748

Nie, H. T., and Tao, J. H. (2008). Impact of coastal exploitation on the ecoenvironment of Bohai Bay. Ocean Eng. 26, 44-50. doi: 10.3969/j.issn.1005-9865. 2008.03.008

Oleszczuk, B., Grzelak, K., and Kdra, M. (2021). Community structure and productivity of arctic benthic fauna across depth gradients during springtime. Deep Sea Res. Part I 170:103457. doi: 10.1016/j.dsr.2020.103457

Pelletier, M. C., Gold, A. J., Heltshe, J. F., and Buffum, H. W. (2010). A method to identify estuarine macroinvertebrate pollution indicator species in the Virginian Biogeographic Province. Ecol. Indic. 10, 1037-1104. doi: 10.1016/j. ecolind.2010.03.005

Peng, S., Zhou, R., Qin, X., Shi, H., and Ding, D. (2013). Application of macrobenthos functional groups to estimate the ecosystem health in a semienclosed bay. Mar. Poll. Bull. 74, 302-310. doi: 10.1016/j.marpolbul.2013. 06.037

Pinto, R., Patricio, J., Baeta, A., Fath, B. D., Neto, J. M., and Marques, J. (2008). Review and evaluation of estuarine biotic indices to assess benthic condition. Ecol. Indic. 9, 1-25. doi: 10.1016/j.ecolind.2008.01.005

Quan, Q. M., Xiao, Y. Y., Xu, S. N., Fu, F. F., Li, C. H., and Liu, Y. (2020a). Seasonal variation in Macrozoobenthos community structure and its relation to environmental factors in Jiaozhou Bay. Chin. J. Ecol. 39, 4110-4120. doi: 10.13292/j.1000-4890.202012.027 
Quan, Q. M., Xu, S. N., Xiao, Y. Y., and Li, C. H. (2020b). Secondary productivity of Macrozoobenthos in Jiaozhou Bay. J. Fish. Sci. Chin. 27, 414-426. doi: 10.3724/ SP.J.1118.2020.190211

Shojaei, M. G., Gutow, L., Dannheim, J., Pehlke, H., and Brey, T. (2015). Functional Diversity and Traits Assembly Patterns of Benthic Macrofaunal Communities in the Southern North Sea. United States: Springer International Publishing. 183-195. doi: 10.1007/978-3-319-13865-7_20

Simboura, N., Papathanassiou, E., and Sakellariou, D. (2007). The use of a biotic index (Bentix) in assessing long-term effects of dumping coarse metalliferous waste on soft bottom benthic communities. Ecol. Indic. 7, 164-180. doi: 10.1016/ j.ecolind.2005.11.006

Simboura, N., and Zenetos, A. (2002). Benthic indicators to use in ecological quality classification of Mediterranean soft bottom marine ecosystems, including a new biotic index. Mediterr. Mar. Sci. 3, 77-111. doi: 10.12681/mms.249

Snelgrove, P. V. R. (1998). The biodiversity of macrofaunal organisms in marine sediments. Biodivers. Conserv. 7, 1123-1132. doi: 10.1023/A:100886731 3340

Solà, C., and Prat, N. (2006). Monitoring metal and metalloid bioaccumulation in Hydropsyche (Trichoptera, Hydropsychidae) to evaluate metal pollution in a mining river. Whole body versus tissue content. Sci. Total Environ. 359, 221-231. doi: 10.1016/j.scitotenv.2005.04.007

Song, J. M., Yuan, H. M., Li, X. G., and Duan, L. Q. (2020). Ecological environment evolution and nutrient variations in Jiaozhou Bay. Mar. Sci. 44, 106-117. doi: 10.11759/hykx20200220001

Sun, X. X., Sun, S., Zhao, Z. X., and Shen, Z. L. (2011). Long-term changes in nutrient concentration and structure in the Jiaozhou Bay. Oceanol. Limnol. Sin. 42, 662-669. doi: 10.11693/hyhz201105006006

Toussaint, E., Borger, E. D., Braeckman, U., Backer, A. D., Soetaert, K., and Vanaverbeke, J. (2021). Faunal and environmental drivers of carbon and nitrogen cycling along a permeability gradient in shallow North Sea sediments. Sci. Total Environ. 767:144994. doi: 10.1016/j.scitotenv.2021.144994

Wang, C. X., Li, Y. Y., and Xu, S. Q. (2010). Biological monitoring and its application in environmental monitoring. Asian J. Ecotoxicol. 5, 628-638. doi: 10.1360/972010-1322

Wang, H. F., Li, X. Z., and Wang, J. B. (2011). Macrobenthic composition and its changes in the Jiaozhou Bay during 2000-2009. Oceanol. Limnol. Sin. 42, 738-752. doi: 10.11693/hyhz201105015015

Wang, L., Fan, Y., Yan, C. J., Gao, C. Z., Xu, Z. D., and Liu, X. S. (2017). Assessing benthic ecological impacts of bottom aquaculture using macrofaunal assemblages. Mar. Poll. Bull. 114, 258-268. doi: 10.1016/j.marpolbul.2016. 09.032

Wu, H. Y., Chen, K. L., Zhang, P., Fu, S. F., Hou, J. P., and Chen, Q. H. (2013). Eco-environmental quality assessment of Luoyuan Bay, Fujian Province of East China based on biotic indices. Chin. J. Appl. Ecol. 24, 825-831. doi: 10.13287/j. 1001-9332.2013.0228

Xiao, C. L., Chen, L. F., and Li, Y. B. (2017). Distribution characteristics and potential risk assessment of heavy metals in the sediment of Jiaozhou Bay. China Sciencepap. 12, 1079-1086. doi: 10.3969/j.issn.2095-2783.2017.09.019

Xu, F., Wang, J. Q., Cai, W. Q., Wei, J. M., and Han, X. M. (2021). Macrozoobenthos functional feeding groups and its relationship with environmental factors in the Tianjing coastal area. Oceanol. Limnol. Sin. 52, 186-195. doi: 10.11693/hyhz20200400108

$\mathrm{Xu}, \mathrm{K} . \mathrm{D}$. (2011). Biodiversity and biogeography of marine macrobenthos: progress and prospect. Biodivers. Sci. 19, 661-675. doi: 10.3724/SP.J.1003.2011.15121

Yang, H., Li, G. Q., Zhou, Y., Liu, Y. J., and Wang, M. M. (2018). Tidal zone dynamics in Jiaozhou Bay in recent 30 years. J. Appl. Oceanogr. 37, 294-230. doi: 10.3969/J.ISSN.2095-4972.2018.02.018

Yang, M., Li, X. Z., Xu, Y., Wang, H. F., and Zhang, B. L. (2016). Seasonal variations in macrobenthic communities in the subtidal zones of Jiaozhou Bay. Biodivers. Sci. 24, 820-830. doi: 10.17520/biods.2015264
Yang, X. J., Cui, W. Y., Zhang, M. S., Chen, and Yu, Z. S. (2021). Preliminary study on the ecology of Macrobenthos in Jiaozhou Bay. Adv. Mar. Sci. 39:1. doi: 10.3969/j.issn.1671-6647.2021.01.009

Yin, Z. Y., Li, J. S., Huang, J., Wang, S. L., Zhang, F. F., and Zhang, B. (2021). Steady increase in water clarity in Jiaozhou Bay in the Yellow Sea from 2000 to 2018: observations from MODIS. J. Oceanol. Limnol. 39, 800-813. doi: 10. 1007/S00343-020-0124-4

Yoon, S. J., Hong, S., Kim, H. G., Lee, J., Kim, T., Kwon, B. O., et al. (2021). Macrozoobenthic community responses to sedimentary contaminations by anthropogenic toxic substances in the Geum River Estuary, South Korea. Sci. Total Environ. 763:142938. doi: 10.1016/j.scitotenv.2020.142938

Ysebaert, T., and Herman, P. M. J. (2002). Spatial and temporal variation in benthic macrofauna and relationships with environmental variables in an estuarine, intertidal soft-sediment environment. Mar. Ecol. Progr. 244, 105-124. doi: 10. 3354/meps244105

Yu, H. Y., Li, X. Z., Li, B. Q., Wang, J. B., and Wang, H. F. (2006). The species diversity of macrobenthic fauna in Jiaozhou Bay. Acta Ecol. Sin. 26, 416-422. doi: 10.3321/j.issn:1000-0933.2006.02.014

Yuan, Y. A., Rojas, I. J., and Wang, X. H. (2020). Response of water-exchange capacity to human interventions in jiaozhou bay, china. Estuar. Coast. Shelf Sci. 249:107088. doi: 10.1016/j.ecss.2020.107088

Zenetos, A., Hatzianestis, J., Lantzouni, M., Simboura, M., Sklivagou, E., and Arvanitakis, G. (2004). The Eurobulker oil spill: mid-term changes of some ecosystem indicators. Mar. Poll. Bull. 48, 122-131. doi: 10.1016/S0025326X(03)00370-9

Zhang, F., Sun, X. X., Zhou, Y., Zhao, C. J., Du, Zh.H, and Liu, R. Y. (2017). Ecosystem health assessment in coastal waters by considering spatio-temporal variations with intense anthropogenic disturbance. Environ. Model. Softw. 96, 128-139. doi: 10.1016/j.envsoft.2017.06.052

Zhang, L., Xiong, L. L., Li, J. L., and Huang, X. P. (2021). Long-term changes of nutrients and biocenoses indicating the anthropogenic influences on ecosystem in Jiaozhou Bay and Daya Bay, China. Mar. Poll. Bull. 168:112406. doi: 10.1016/ j.marpolbul.2021.112406

Zhang, X. Q., and Sun, Y. L. (2007). Study on the environmental capacity in Jiaozhou Bay. Mar. Environ. Sci. 25, 347-359.

Zhang, Z. Z., Wang, L., Yang, W. B., Cao, K., and Li, J. L. (2015). Impact of marine habitat changes on macro-benthos communities in Bohai Bay. J. Fish. Sci. China. 22, 106-112. doi: 10.3724/SP.J.1118.2015.00090

Zheng, B., Zhao, X., Liu, L., Li, Z., Lei, K., Zhang, L., et al. (2011). Effects of hydrodynamics on the distribution of trace persistent organic pollutants and macrobenthic communities in Bohai Bay. Chemosphere 84, 336-341. doi: 10. 1016/j.chemosphere.2011.04.006

Conflict of Interest: The authors declare that the research was conducted in the absence of any commercial or financial relationships that could be construed as a potential conflict of interest.

Publisher's Note: All claims expressed in this article are solely those of the authors and do not necessarily represent those of their affiliated organizations, or those of the publisher, the editors and the reviewers. Any product that may be evaluated in this article, or claim that may be made by its manufacturer, is not guaranteed or endorsed by the publisher.

Copyright (c) $2021 \mathrm{Lu}, \mathrm{Xu}, \mathrm{Xu}$ and Liu. This is an open-access article distributed under the terms of the Creative Commons Attribution License (CC BY). The use, distribution or reproduction in other forums is permitted, provided the original author(s) and the copyright owner(s) are credited and that the original publication in this journal is cited, in accordance with accepted academic practice. No use, distribution or reproduction is permitted which does not comply with these terms. 